\title{
Meningitis Caused by Alcaligenes xylosoxidans in a Patient with HIV/AIDS
}

\author{
F. Espinoza-Gómez ${ }^{1,2}$, O.A. Newton-Sánchez ${ }^{2}$, V. Melnikov ${ }^{2}$, O. Virgen-González $^{1}$ and J. Unrau ${ }^{2}$ \\ ${ }^{1}$ Hospital Regional Universitario, Secretaría de Salud y Bienestar Social del Estado de Colima; ${ }^{2}$ Facultad de Medicina de la Universidad de \\ Colima; Colima, Mexico
}

\begin{abstract}
The purpose of the present work was to inform about the first case of meningitis associated to the bacteria Alcaligenes xylosoxidans in a patient with HIV/AIDS. The patient was a 46-year-old male, with the antecedent of have been diagnosed for HIV/ AIDS, who attended in the Hospital Universitario de Colima, Mexico, with fever, shock and meningismus. The study of the cerebrospinal fluid showed pleocytosis, elevated protein levels and hypoglycorrhachia. The culture yielded the presence of Alcaligenes xylosoxidans with sensitivity to ciprofloxacin. After 14 days of treatment with this antibiotic, the patient showed neurologic improvement and was able to continue with his outpatient antiretroviral treatment. The present case shows the importance of the inclusion of this bacterium in the differential diagnosis of the neurological infections in HIV/AIDS patients and emphasizes the importance of considering the bacterial meningitis in this population.
\end{abstract}

Key words: Meningitis, Alcaligenes xylosoxidans, HIV/AIDS.

Central nervous system (CNS) infections constitute one of the most serious problems in patients infected with the human immunodeficiency virus or with acquired immunodeficiency syndrome (HIV/AIDS). The most frequently involved microorganisms are: Mycobacterium tuberculosis, Cryptococcus neoformans and Toxoplasma gondii (90\%) [1], in addition to fungi such as Aspergillus fumigatus, Nocardia asteroides, Histoplasma capsulatum and viruses from the Herpesvirus and Cytomegalovirus families or HIV itself [2], as well as disease by prions like Creutzfeldt-Jakob.

With the exception of tuberculosis, bacterial CNS infections in patients with AIDS are relatively rare but deserve special attention due to their particularly aggressive behavior. Their timely diagnosis results in significant recovery rates when adequate antibiotics are used. Among AIDS patients, the following non-tuberculosis bacterial neurological infections have been reported: Streptococcus pyogenes, $H$. influenzae, Neisseria meningitides, S. pneumoniae, E. coli, Salmonella sp., Treponema pallidum, Enterococcus fecalis, Listeria monocitogenes and Bacteroides fragilis [3,4].

Alcaligenes xylosoxidans, also known as Achromobacter xylosoxidans, is a Gram-negative, nonglucose-fermenting, aerobic, oxidase- and catalase-positive bacterium, frequently isolated from aqueous environments [5]. It sporadically causes disease in humans, particularly nosocomial infections in immune suppressed patients and newborns, manifested as chronic purulent otitis, keratitis, bacteremia, meningitis, urinary tract infections and osteomyelitis [6-9]. In patients with AIDS, some cases of

Received on 25 August 2007; revised 21 October 2007.

Address for correspondence: Dr. Francisco Espinoza- Gómez, Laboratorio de Salud Pública, Facultad de Medicina de la Universidad de Colima, Avenida Universidad 333, Colonia las Víboras, Colima, Colima, México, CP 28040. E mail: fespin@cgic.ucol.mx.

The Brazilian Journal of Infectious Diseases 2007;11(6):603-604. (C) 2007 by The Brazilian Journal of Infectious Diseases and Contexto Publishing. All rights reserved. pneumonia, pulmonary abscess and bacteremia caused by these bacteria have been documented $[10,11]$. However, after consulting the medical literature (Medline, Current Contents and EMBASE), during the period comprised between 1982 and 2006, it was not possible to find any report of neurological infection attributable to this bacterium in patients with AIDS. For this reason, we report the first case of meningitis caused by apparently community-acquired A. xylosoxidans, in a patient with HIV/ AIDS.

\section{Case Report}

Forty-six-year-old male, farmer, with a history of homosexual practices, diagnosed with AIDS five months earlier after presenting diarrhea, fever, weight loss, and positive ELISA and Western Blot (WB) tests, without antiretroviral treatment. For the last ten days the patient had presented watery diarrhea, fever, asthenia, adynamia, confusion and muscular rigidity. Physical examination revealed temperature $=39.5{ }^{\circ} \mathrm{C}$, blood pressure $=90 / 50$ $\mathrm{mmHg}$, heart rate $=120 \mathrm{bpm}$ and respiratory rate $=32 \mathrm{bpm}$. The patient was diaphoretic, disoriented in time and space, very restless, with nuchal and lower extremity rigidity, also presenting oral candidiasis and hepatosplenomegaly. The laboratory results reported: hemoglobin: $9.7 \mathrm{~g} / \mathrm{dL}$, leukocytes: $2,500 / \mathrm{mm}^{3}$, neutrophils: $57 \%$, lymphocytes: 33\%, monocytes: $10 \%$, platelets: $52,000 / \mathrm{mm}^{3}$, serum creatinine: $1.9 \mathrm{mg} / \mathrm{dL}$, serum sodium: $129 \mathrm{mEq} / \mathrm{L}$, serum potassium: $4 \mathrm{meEq} / \mathrm{L}$, total protein: $6.5 \mathrm{~g} / \mathrm{dL}$, serum albumin: $1.9 \mathrm{~g} / \mathrm{dL}$. Arterial gases showed metabolic acidosis. The cytochemistry of cerebrospinal fluid (CSF) revealed a cloudy aspect, with glucose of $70 \mathrm{mg} / \mathrm{dL}$ (serum glucose: $160 \mathrm{mg} / \mathrm{dL})$, protein $450 \mathrm{mg} / \mathrm{dL}$ and 4,750 cells $(70 \%$ polymorphonuclear cells). Gram, Ziehl Nielsen and India ink stains were negative. Stool and urinanalysis, chest xray and CAT scan were normal. The patient was treated with lactated Ringer's solutions, dopamine, midazolam, cefotaxime and intravenous ciprofloxacin, with subsequent improvement of hypotension, diarrhea and metabolic 
acidosis. Two negative blood cultures were reported, meanwhile Alcaligenes xylosoxidans subsp. xylosoxidans, sensitive to ciprofloxacin, was isolated from CSF (Microscan Walkaway $96 \AA$, Dade BEHRING LABS). ELISA and WB tests confirmed HIV. A CD4 count resulted in 276/dL. Treatment with lopinavir, ritonavir and tenofovir was started. Following the remission of the neurological symptoms, the patient was discharged after two weeks of treatment with ciprofloxacin and the aforementioned antiretroviral therapy.

\section{Discussion}

This report adds Alcaligenes xyloxosidans to the list of possible CNS infectious agents in patients with HIV/AIDS. Despite the fact that Alcaligenes xyloxosidans can be confused with Pseudomonas sp. [6], the biochemical characteristics detected by automated systems (Microscan) allow for a reliable identification [12,13]. Due to the low notification of infections caused by this bacterium, its epidemiology is not known. It is proposed that, in humans, inoculation is mainly nosocomial via contaminated catheters $[5,14]$. There are isolated reports of community-acquired infections5, as appears to be in this case, although the primary source of inoculation is unknown. Risk factors associated with mortality due to this microorganism are: more than 65 years of age, nosocomial acquisition and neutropenia [6,15], the last one present in our patient. A. xylosoxidans' susceptibility pattern indicates that it requires a very specific treatment. The recommended empirical regimen consists in piperacillin, imipenem or ceftazidime. In this case, the bacteria was sensitive to ciprofloxacin, in contrast to that reported by Shie, who found that only $20-25 \%$ of strains were sensitive to quinolones [5]. possibly due to the fact that the pattern of susceptibility to antibiotics can be modulated by the HIV infection [3]. The initial treatment with ciprofloxacin in this patient was directed to a possible enteritis caused by Gram-negative bacilli, and was continued after isolating the bacteria from CSF and obtaining the antibiogram. This could explain his rapid and dramatic recovery. This case emphasizes the importance of considering less frequent etiologies among CNS infections in patients with HIV/AIDS, especially bacterial infections, since they could have a better prognosis if adequately identified.

\section{References}

1. Roullet E. Opportunistic infections of the central nervous system during HIV-1 infection. J Neurol 1999;246:23743.

2. Mamidi A., DeSimone J.A., Pomerantz R.J. Central nervous system infections in individuals with HIV-1 infection. J Neuroviol 2002;8:158-67.

3. Molyneux E.M., Tembo M., Kayira K., et al. The effect of HIV infection on paediatric bacterial meningitis in Blantyre, Malawi. Arch Dis Child 2003;88:1112-18.

4. Leonard M.K., Murrow J.R., Jurado R., Gaynes R. Salmonella meningitis in adults infected with HIV: case report and review of the literature. Am J Med Sci 2002;323:266-8.

5. Shie S.S., Huang C.T., Leu H.S. Characteristics of Achromobacter xylosoxidans bacteremia in northern Taiwan. J Microbiol Immunol Infect 2005;38:277-82.

6. Tsay R.W., Lin L.C., Chiou C.S., et al. Alcaligenes xylosidans bacteremia: clinical features and microbiological characteristics of isolates. J Microbiol Immunol Infect 2005;38:194-9.

7. Oh J.Y., Shin Y.J., Wee W.R. A case of epidemic keratoconjunctivitis complicated by Alcaligenes xylosidans infection. Korean $\mathrm{J}$ Ophthalmol 2005; 19:233-4.

8. Weitkamp J.H., Tang Y.W., Hass D.W., et al. Recurrent Achromobacter xylosoxidans bacteremia associated with persistent lymph node infection in a patient with hyperimmunoglobulin $M$ syndrome. Clin Infect Dis 2000;31:1183- 7 .

9. Ben-Salem N., Salem N., Monastiri K., et al. Neonatal meningitis due to Alcaligenes xylosoxidans contaminating aqueous solution of eosin. Arch Pediatr 1999;6:226-7.

10. Manfredi R., Nanetti A., Ferri M., Chiodo F. Bacteremia and respiratory involvement by Alcaligenes xylosoxidans in patients infected with the human immunodeficiency virus. Eur J Clin Microbiol Infect Dis 1997;16:933-8.

11. Gradon J.D., Mayrer A.R., Hayes J. Pulmonary abscess associated with Alcaligenes xylosoxidans in a patient with AIDS. Clin Infect Dis 1993; $17: 1071-2$.

12. Tenover F.C., Mizuki T.S., Carlson L.G. Evaluation of autoSCAN-W/A automated microbiology system for the identification of non-glucose-fermenting Gram-negative bacilli. J Clin Microbiol 1990;28:1628-34.

13. O'Hara C.M., Miller J.M. Ability of the MicroScan rapid Gramnegative ID type 3 panel to identify nonenteric glucosefermenting and nonfermenting Gram-negative bacilli. J Clin Microbiol 2002;40:3750-2.

14. Cieslak T.J., Raszka W.V. Catheter-associated sepsis due to Alcaligenes xylosoxidans in a child with AIDS. Clin Infect Dis 1993; $16: 592-3$.

15. Gomez-Cerezo J., Suarez I., Rios J.J., et al. Achromobacter xylosoxidans bacteremia: a 10-year analysis of 54 cases. Eur J Clin Microbiol Infect Dis 2003;22:360-3. 